\title{
Abnormal Cerebrovascular Reactivity in Patients with Parkinson's Disease
}

\author{
Carlos Henrique Ferreira Camargo, ${ }^{1}$ Eduardo Antunes Martins, ${ }^{1}$ \\ Marcos Christiano Lange, ${ }^{2}$ Henrique Alvaro Hoffmann, ${ }^{1}$ \\ Jissa Jeanete Luciano, ${ }^{1}$ Marcelo Rezende Young Blood, ${ }^{1}$ Marcelo Derbli Schafranski, \\ Marcelo Machado Ferro, ${ }^{1}$ and Edmar Miyoshi ${ }^{1}$ \\ ${ }^{1}$ State University of Ponta Grossa, Avenida General Carlos Cavalcanti 4748, 84030-900 Ponta Grossa, PR, Brazil \\ ${ }^{2}$ Hospital de Clínicas, Federal University of Paraná, Rua General Carneiro 181, 80060-900 Curitiba, PR, Brazil \\ Correspondence should be addressed to Carlos Henrique Ferreira Camargo; chcamargo@uol.com.br
}

Received 28 March 2015; Revised 4 June 2015; Accepted 7 June 2015

Academic Editor: Antonio Pisani

Copyright (C) 2015 Carlos Henrique Ferreira Camargo et al. This is an open access article distributed under the Creative Commons Attribution License, which permits unrestricted use, distribution, and reproduction in any medium, provided the original work is properly cited.

\begin{abstract}
Background. Orthostatic hypotension $(\mathrm{OH})$ is an important nonmotor manifestation of Parkinson's disease (PD). Changes in cerebrovascular reactivity may contribute to this manifestation and can be monitored using transcranial Doppler. Objective. To identify possible changes in cerebrovascular reactivity in patients with $\mathrm{OH}$. Methods. Twenty-two individuals were selected and divided into three groups: with and without $\mathrm{OH}$ and controls. Transcranial Doppler was used to assess basal mean blood flow velocity, postapnea mean blood flow velocity, percentage increase in mean blood flow velocity, and cerebrovascular reactivity as measured by the breath-holding index. Results. PD patients had lower values of basal velocity $(p=0.019)$, postapnea velocity $(p=0.0015)$, percentage increase in velocity $(p=0.039)$, and breath-holding index $(p=0.04)$ than the controls. Patients with $\mathrm{OH}$ had higher values of basal velocity $(p=0.09)$ and postapnea velocity $(p=0.19)$ but lower values of percentage increase in velocity $(p=0.22)$ and breath-holding index $(p=0.32)$ than patients without $\mathrm{OH}$. Conclusions. PD patients present with abnormalities in a compensatory mechanism that regulates cerebral blood flow. $\mathrm{OH}$ could be an indicator of these abnormalities.
\end{abstract}

\section{Introduction}

Parkinson's disease (PD) is characterized by slow degeneration of specific neurons in the enteric, peripheral, and central nervous system [1]. Analysis of lesions in PD by Braak et al. [2] showed that the disease progresses in six stages in a caudorostral direction, starting in caudal regions of the brain stem, such as the dorsal motor nuclei of the glossopharyngeal and vagus nerves and the anterior olfactory nucleus, and spreading to practically the whole cortex [3]. Based on these pathological findings and the clinical presentation of the disease, the definition of PD as only a motor disease is believed to be clearly inadequate. Dysautonomias are one of the most important nonmotor complications of PD [4], and orthostatic hypotension $(\mathrm{OH})$ is quite a common complaint [5], occurring in around $40 \%$ of PD patients [6].
A drop in systemic arterial blood pressure is normally compensated for by a sympathetically mediated increase in vascular tone and cerebral vasodilation. PD patients, however, present with worse hemodynamic parameters because of degeneration of central and peripheral nuclei (brainstem, cerebral cortex, spinal cord, and autonomic ganglia [2]); baroreflex failure, with a reduction in the number of catecholaminergic neurons in the nucleus of the solitary tract [7]; diffuse cardiac noradrenergic denervation of the left ventricle [8]; abnormal pressure natriuresis and diuresis due to loss of specific neurotransmitters [9]; suboptimal release of norepinephrine when the patient stands up [10], with an increase in the number of $\alpha$-adrenoreceptors in an attempt to control sympathetic dysfunction in this position [11]; and the presence of Lewy bodies in axons in the paravertebral sympathetic chain and the stellate ganglion [10]. Therefore, a 
decrease in sympathetic tone in PD patients with $\mathrm{OH}$ is well known and the mechanisms involved are well established, which is not yet the case for the mechanisms responsible for maintaining cerebral blood flow [12].

Transcranial Doppler (TCD) allows cerebral blood flow velocity (cBFV) and the contractility of cerebral vessels to be measured dynamically and with high temporal resolution [13]. An increase in the concentration of $\mathrm{CO}_{2}$ in the blood stream leads to vasodilation of the intracranial microcirculation, which can be observed in TCD as an increase in cBFV. This change in $\mathrm{cBFV}$ in response to a vasodilatory stimulus is known as cerebrovascular reactivity (CVR) [14]. Various techniques can be used to estimate CVR $[15,16]$, such as measurement of the percentage change in the mean blood flow velocity (mBFV) in the middle cerebral artery (MCA) between hyperventilation and inspiration of increasing concentrations of $\mathrm{CO}_{2}$ or the inspiration of $5 \% \mathrm{CO}_{2}$. However, the technique based on the use of breath-holding as the vasodilatory stimulus is the most suitable as it is both practical and easy-to-use [16]. The breath-holding index (BHI) was first described by Ratnatunga and Adiseshiah [17], who observed that the change in the MBFV of the MCA after a period of apnea without prior forced inspiration divided by the apnea duration gave an estimate of the change in cerebral blood flow and therefore CVR. Markus and Harrison [16] showed that this methodology was equivalent to those based on inspiration of $\mathrm{CO}_{2}$ and also defined an ideal time and minimum apnea duration (30 and 15 seconds, resp.).

Despite the existence of these various approaches, to the authors' knowledge there are no studies that provide absolutely conclusive findings about the changes in CVR in PD patients. While the first studies to correlate the findings of TCD with $\mathrm{OH}$ and $\mathrm{PD}$ did not find any changes, more recent studies using other approaches found significant changes in CVR in patients with PD compared with controls. The present study is the first to use the BHI to show that these changes occur and, furthermore, is one of the few ones to compare $\mathrm{OH}$ patients with patients without $\mathrm{OH}$ rather than only with controls.

The aim of the present study was to identify possible changes in CVR measured using the BHI in patients with $\mathrm{OH}$ associated with PD.

\section{Materials and Methods}

The study sample consisted of 20 patients with a confirmed diagnosis of PD according to the UK Parkinson's Disease Society Brain Bank clinical diagnostic criteria [18] who were being followed up regularly at the Neurology Service at the Campos Gerais Regional University Hospital (HURCG) [19].

Patients with Parkinsonism-plus disease, Parkinsonism as an associated feature of heredodegenerative diseases, and secondary Parkinsonism were excluded, as were patients who were using dopamine agonists and those who refused to sign the voluntary informed-consent form.

The study was approved by the State University of Ponta Grossa (UEPG) Research Ethics Committee (COEP) (reference number FA 22591).
2.1. Clinical Assessment. Patients were evaluated clinically, neurologically, and for the presence of $\mathrm{OH}$ [19], which was defined as a drop of at least $20 \mathrm{mmHg}$ in systolic blood pressure and/or a drop of at least $10 \mathrm{mmHg}$ in diastolic blood pressure as a result of a change from a supine to a standing position after one minute [11]. Ultrasound studies of extracranial and intracranial blood flow were performed to exclude occlusive diseases.

Patients were then divided into two groups: those with $\mathrm{OH}(n=9)$ and those without $(n=11)$. Two patients from the group with $\mathrm{OH}$ and five from the group without $\mathrm{OH}$ were not examined by TCD as they did not consent to proceed with the study. One patient from the group with $\mathrm{OH}$ and one from the group without $\mathrm{OH}$ were excluded from the study because of inadequate temporal acoustic windows. A control group ( $n=11$ ) was formed from healthy individuals recruited among the patients' relatives and hospital staff. The final study population therefore consisted of six patients in the group with $\mathrm{OH}$, five in the group without $\mathrm{OH}$, and eleven controls.

2.2. Transcranial Doppler (TCD). TCD was carried out in a quiet, dimly lit room. Tests were carried out between 9 am and noon Brasília time. All the patients were required to lie down in the examination room for 5 minutes before the start of the test, which lasted between 15 and 20 minutes. Patients were instructed not to use the first dose of levodopa (L-dopa) in the morning. All tests were performed by a single researcher who had previous experience in TCD. The researcher was unaware of the clinical condition of each participant.

An S4-2 $2 \mathrm{MHz}$ sector-phased array transducer coupled to a Philips HD11 XE Ultrasound System (Philips@, Philips Medical Systems B.V., Netherlands) was used to assess the M1 segment (45-55 mm deep) of the MCA in both sides.

The tests started on the left MCA and the following information was collected: basal mean blood flow velocity (bBFV) in $\mathrm{cm} / \mathrm{s}$; postapnea mean blood flow velocity $(\mathrm{aBFV})$ in $\mathrm{cm} / \mathrm{s}$; and duration of apnea in $s$. Throughout the procedure the transducer was kept in the place that had been initially identified as suitable for measuring the desired parameters. CVR (absolute value) was estimated using the BHI [16], which is given by the following formula:

$$
\mathrm{BHI}=\frac{\{\% \mathrm{IBFV} / \mathrm{bBFV}\}}{T},
$$

$$
\text { where } \% \mathrm{IBFV}=[(\mathrm{aBFV}-\mathrm{bBFV}) \cdot 100] \text {, }
$$

where $\mathrm{BHI}=$ breath-holding index; $\mathrm{aBFV}=$ mean postapnea blood flow velocity; bBFV = basal mean blood flow velocity; $T=$ duration of apnea in seconds. Values of BHI of less than 0.70 were considered abnormal [16]. The percentage increase in blood flow velocity (\%IBFV) was analyzed.

2.3. Statistical Analysis. The statistical differences between the means of the groups were measured using the twotailed Student's $t$-test for normal distributions and the MannWhitney test for nonnormal distributions. Fisher's exact test was used for categorical variables. The effect size was analyzed 
using the odds ratio for categorical variables and Cohen's $d$ coefficient for continuous variables (0.2: weak effect; 0.5 : moderate effect; and 0.8: strong effect). The results are given as mean \pm standard deviation (SD) or as an odds ratio (OR) and $95 \%$ confidence interval (CI) (OR (95\%CI)). $p$ values of less than 0.05 were considered statistically significant. The analysis was performed with MedCalc 5.1 (Belgium) (MedCalc version 11.5.1-MedCalc, Mariakerke, Belgium) and Microsoft Excel.

\section{Results}

3.1. Demographics. Of the patients with PD, six (54.54\%) had $\mathrm{OH}$, but only two $(33.3 \%)$ of these patients presented with complaints compatible with $\mathrm{OH}$. There were no significant differences in age $(67.36 \pm 11.73$ versus $64.727 \pm 11.867$, $p=0.61$ ) or gender between the control group and patients with $\mathrm{PD}$. The ratio of men to women was 2.67:1 (eight men, $72.74 \%$, and three women, $27.27 \%$ ). The control group consisted of seven men (63.64\%) and four women (36.36\%), giving a ratio of men to women of $1.75: 1$ (Table 1$)$. There were no significant differences in terms of L-dopa use, age, and gender between patients with and without $\mathrm{OH}$ (Table 2).

3.2. CVR. Of all the patients with $\mathrm{PD}$, six (54.5\%) had an abnormal BHI. Four of these $(66.7 \%)$ were from the group with $\mathrm{OH}$ and two (40\%) from the group without $\mathrm{OH}, p=$ 0.57 (3 (0.25-35.33)). There was a greater percentage of abnormal BHI values in the PD group (54.5\%) than in the control group (27.3\%), $p=0.04$ (4.75 (1.07-21.14)).

3.3. Relationship between TCD Findings and $\mathrm{OH}$. Patients with PD had lower values of bBFV, aBFV, \%IBFV, and BHI than controls (Table 3 ). Individuals with $\mathrm{OH}$ had lower values of bBFV, aBFV, \%IBFV, and BHI than controls (Table 4). PD patients without $\mathrm{OH}$ also had values of $\mathrm{bBFV}$ and $\mathrm{aBFV}$ that were significantly lower than in controls (Table 5).

When the results for PD patients with and without $\mathrm{OH}$ were compared, the former had higher values of bBFV $(49.93 \pm 12.36$ versus $43.39 \pm 9.65, p=0.09$; Cohen's $d=$ $0.59)$ and $\mathrm{aBFV}(61.27 \pm 12.26$ versus $56.25 \pm 13.73, p=0.19$; Cohen's $d=0.39)$ and lower values of \%IBFV $(24.65 \pm 14.08$ versus $30.54 \pm 20.64 ; p=0.22$; Cohen's $d=0.33)$ and BHI $(0.88 \pm 0.5$ versus $1.04 \pm 0.98 ; p=0.32$; Cohen's $d=-0.21)$; however, these results were not statistically significant.

\section{Discussion}

The prevalence of $\mathrm{OH}$ in the study sample was $54.54 \%$, and $33 \%$ of the patients were symptomatic. These figures agree with the prevalence reported in the literature of $40-$ $60 \%$ among PD patients [6] with only $20 \%$ reporting some symptoms [20].

The present study has shown that PD patients have altered CVR compared with controls. To our knowledge, it is the first study to establish a correlation between BHI and PD. Niehaus et al. [21], using TCD and the tilt-table test, reported a small increase in heart rate (HR) and a greater, more prolonged
TABLE 1: Comparison of controls and PD patients.

\begin{tabular}{lccc}
\hline & PD & Controls & $p$ \\
\hline Mean age (years) & $67.36 \pm 11.73$ & $64.727 \pm 11.867$ & $p=0.606$ \\
\hline Gender & & & $p=1$ \\
M & 8 & 7 & \\
F & 3 & 4 & \\
\hline
\end{tabular}

Note: $\mathrm{PD}=$ Parkinson's disease; $\mathrm{OH}=$ orthostatic hypotension.

drop in arterial blood pressure (ABP) in $\mathrm{PD}$ patients who were tilted close to the upright position. However, no changes in $\mathrm{CBFV}$ were observed in these patients, whose CA was similar to that of the control group. Angeli et al. [22] observed a hypotensive response to orthostatic stress, with intracranial vasodilation and lower diastolic pressure in PD patients monitored with TCD during tilt-table testing. Gurevich et al. [12] compared CA and CVR in PD patients with multiple system atrophy (MSA) and pure autonomic failure (PAF) using TCD, the acetazolamide test, and the tilt-table test but failed to find any change in CVR.

Our findings of altered CVR and lower cBFV agree with more recent studies that used TCD to analyze cerebral hemodynamics in PD patients [23, 24]. Vokatch et al. [11] used TCD and thigh cuffs to assess CA and found striking differences in $\mathrm{mBFV}$ between controls and PD patients, especially after a reduction in blood pressure, providing strong evidence of impaired CA in patients with this disorder. Furthermore, L-dopa did not appear to influence the changes in these parameters. Using the cold pressor test, Tsai et al. [24] found similar changes in cBFV. However, they did not take into account whether their patients were using L-dopa or not in their study. Bouhaddi et al. [25] used TCD and the tilt-table test to compare PD patients taking and not taking L-dopa and concluded that this medication could further impair autonomic control of heart rate and blood pressure.

Previously published studies of $\mathrm{OH}$ in PD patients [11, $21,22,24]$ that investigated $\mathrm{CA}$ did not reach definitive conclusions about its impact on $\mathrm{cBFV}$ or the possible impact of the use of L-dopa on autonomic dysfunction [25].

In the present study, the values of bBFV, \%IBFV, and BHI were lower in $\mathrm{PD}$ patients with $\mathrm{OH}$ than in controls. CVR can be estimated by measuring the change in $\mathrm{CBFV}$ in response to vasodilatory stimuli [14]. bBFV and aBFV represent $\mathrm{cBFV}$ at baseline and after a normally vasodilatory stimulus, respectively, and \%IBFV is the relative difference between them [16]. Previous studies did not identify these differences even though they used methods that were theoretically similar to the method using breath-holding as a vasodilatory stimulus [16]. This probably occurred because these studies used $8 \%$ $\mathrm{CO}_{2}$ instead of BHI.

The probable pathophysiological explanation for the TCD findings observed in the present study is that hemodynamically compromised tissue is supplied by arterioles that are already maximally, or near maximally, dilated. A stimulus that is normally vasodilatory is therefore unable to produce an adequate response [16]. It appears that $\mathrm{OH}$ patients have greater degeneration of the sympathetic nervous system, leading to significant hemodynamic impairment. Hence, all 
TABLE 2: Clinical and demographic data for the PD patients with and without orthostatic hypotension.

\begin{tabular}{|c|c|c|c|}
\hline & $\mathrm{PD}$ without $\mathrm{OH}$ & PD with $\mathrm{OH}$ & $p$ \\
\hline Mean age (years) & $62 \pm 14.16$ & $71.8 \pm 7.89$ & $p=0.657$ \\
\hline \multicolumn{4}{|l|}{ Gender } \\
\hline M & 3 & 5 & \\
\hline $\mathrm{F}$ & 2 & 1 & \\
\hline Age of onset (years) & $56 \pm 16.58$ & $68.5 \pm 7.4$ & $p=0.176$ \\
\hline Disease duration (years) & $6 \pm 3.54$ & $3.33 \pm 1.03$ & $p=0.169$ \\
\hline Duration of L-dopa use (years) & $4.3 \pm 3.03$ & $3.17 \pm 1.33$ & $p=0.471$ \\
\hline Duration of disease before L-dopa started (years) & $1.7 \pm 2.11$ & $0.17 \pm 0.41$ & $p=0.181$ \\
\hline \multicolumn{4}{|l|}{ Predominance of symptoms } \\
\hline Predominantly akinetic-rigid & 4 & 4 & $p=1$ \\
\hline Predominant tremor & 1 & 2 & $p=1$ \\
\hline Dizziness and falls & & & $p=0.242$ \\
\hline Yes & 2 & 5 & \\
\hline No & 3 & 1 & \\
\hline UPDRS & $11,6 \pm 7,23$ & $15,167 \pm 13,41$ & $p=0.304$ \\
\hline Hoehn and Yahr [1] & $1,8 \pm 1,1$ & $2 \pm 1,1$ & $p=0.385$ \\
\hline
\end{tabular}

Note: $\mathrm{PD}=$ Parkinson's disease; $\mathrm{OH}$ = orthostatic hypotension.

TABLE 3: Cerebral hemodynamic data for PD patients and controls.

\begin{tabular}{lccc}
\hline & PD & Controls & $p$-Cohen \\
\hline $\mathrm{bFV}(\mathrm{cm} / \mathrm{s})$ & $46.41 \pm 11.38$ & $54.42 \pm 12.03$ & 0.019 \\
$\operatorname{aBFV}(\mathrm{cm} / \mathrm{s})$ & $58.88 \pm 12.9$ & $75.15 \pm 20.07$ & 0.0015 \\
$\% \operatorname{IBFV}(\%)$ & $27.45 \pm 17.31$ & $37.94 \pm 20.53$ & 0.039 \\
BHI & $0.96 \pm 0.75$ & $1.35 \pm 0.74$ & 0.04 \\
\hline
\end{tabular}

Note: $\mathrm{PD}=$ Parkinson's disease; $\mathrm{bBFV}=$ basal mean blood flow velocity $(\mathrm{cm} / \mathrm{s}) ; \mathrm{aBFV}=$ mean postapnea blood flow velocity $(\mathrm{cm} / \mathrm{s}) ; \% \mathrm{IBFV}=$ percentage increase in mean velocity during breath-holding (\%); BHI = breath-holding index.

TABLE 4: Cerebral hemodynamic data for PD patients with $\mathrm{OH}$ and controls.

\begin{tabular}{lccc}
\hline & PD and OH & Controls & $p$-Cohen \\
\hline $\operatorname{bBFV~}(\mathrm{cm} / \mathrm{s})$ & $49.93 \pm 12.36$ & $54.42 \pm 12.03$ & 0.16 \\
$\operatorname{abFV~}(\mathrm{cm} / \mathrm{s})$ & $61.27 \pm 12.26$ & $75.15 \pm 20.07$ & 0.02 \\
$\% \operatorname{IBFV}(\%)$ & $24.65 \pm 14.08$ & $37.94 \pm 20.53$ & 0.032 \\
BHI & $0.88 \pm 0.5$ & $1.35 \pm 0.74$ & 0.03 \\
\hline
\end{tabular}

Note: $\mathrm{PD}=$ Parkinson's disease; $\mathrm{OH}=$ orthostatic hypotension; $\mathrm{bBFV}=$ basal mean blood flow velocity $(\mathrm{cm} / \mathrm{s}) ; \mathrm{aBFV}=$ mean postapnea blood flow velocity $(\mathrm{cm} / \mathrm{s}) ; \% \mathrm{IBFV}=$ percentage increase in mean velocity during breath-holding (\%); BHI = breath-holding index.

the cerebrovascular reserve capacity may be used up under basal conditions, and when an increase in blood supply is required these values cannot be compensated for, resulting in the changes observed in $\mathrm{aBFV}$, \%IBFV, and $\mathrm{BHI}$, a drop in pressure and, consequently, $\mathrm{OH}$. $\mathrm{PD}$ patients without $\mathrm{OH}$ probably have less severe autonomic impairment, which is reflected in a lower flow velocity under basal conditions [23, 25]. Therefore, because CVR is less affected in these patients, their response to changes in blood supply requirements is normal and does not lead to $\mathrm{OH}$. A similar hypothesis has
TABLe 5: Cerebral hemodynamic data for PD patients without $\mathrm{OH}$ and controls.

\begin{tabular}{lccc}
\hline & PD without OH & Controls & $p$-Cohen \\
\hline $\operatorname{bBFV~}(\mathrm{cm} / \mathrm{s})$ & $43.39 \pm 9.65$ & $54.42 \pm 12.03$ & 0.008 \\
$\operatorname{abFV~}(\mathrm{cm} / \mathrm{s})$ & $56.25 \pm 13.73$ & $75.15 \pm 20.07$ & 0.057 \\
\%IBFV $(\%)$ & $30.54 \pm 20.64$ & $37.94 \pm 20.53$ & 0.23 \\
BHI & $1.04 \pm 0.98$ & $1.35 \pm 0.74$ & 0.16 \\
\hline
\end{tabular}

NB: PD = Parkinson's disease; $\mathrm{OH}=$ orthostatic hypotension; $\mathrm{bBFV}=$ basal mean blood flow velocity $(\mathrm{cm} / \mathrm{s}) ; \mathrm{aBFV}=$ mean post-apnea blood flow velocity $(\mathrm{cm} / \mathrm{s}) ; \% \mathrm{IBFV}=$ percentage increase in mean velocity during breath-holding (\%); BHI = breath-holding index .

already been proposed by Haubrich et al. [26], although they concluded that autoregulatory mechanisms in PD patients were the same as in healthy individuals.

This study has a number of limitations. Firstly, we assumed that L-dopa does not influence CVR in PD patients $[11,23]$. This could have been confirmed by carrying out two sets of tests, one with and the other without the medication. Secondly, as BHI and similar indexes [16] have only been tested on patients without any neurological condition to estimate CA, it would be useful to investigate these indexes in PD patients. Lastly, as our sample was small, a study with more patients and controls should be carried out to confirm the conclusions.

We have shown that PD patients have abnormal cBFV, indicating that cerebral hemodynamic alterations may also be present in these patients. Individuals with $\mathrm{PD}$ and $\mathrm{OH}$ appear to have altered CVR and great difficulty in satisfying tissue requirements under nonbasal conditions, which could explain the clinical findings for these individuals. Nevertheless, further studies are required to confirm these results. 


\section{Conflict of Interests}

The authors declare that there is no conflict of interests regarding the publication of this paper.

\section{Acknowledgment}

The authors of this paper received financial support from Fundação Araucária. The terms of this arrangement have been reviewed and approved by the State University of Ponta Grossa, Ponta Grossa, Paraná, Brazil, in accordance with its policy on objectivity in research.

\section{References}

[1] M. M. Hoehn and M. D. Yahr, "Parkinsonism: onset, progression and mortality," Neurology, vol. 17, no. 5, pp. 427-442, 1967.

[2] H. Braak, U. Rüb, W. P. Gai, and K. del Tredici, "Idiopathic Parkinson's disease: possible routes by which vulnerable neuronal types may be subject to neuroinvasion by an unknown pathogen," Journal of Neural Transmission, vol. 110, no. 5, pp. 517-536, 2003.

[3] H. Braak and E. Braak, "Development of Alzheimer-related neurofibrillary changes in the neocortex inversely recapitulates cortical myelogenesis," Acta Neuropathologica, vol. 92, no. 2, pp. 197-201, 1996.

[4] D. S. Goldstein, L. Sewell, and Y. Sharabi, "Autonomic dysfunction in PD: a window to early detection?" Journal of the Neurological Sciences, vol. 310, no. 1-2, pp. 118-122, 2011.

[5] L. M. Allcock, K. Ullyart, R. A. Kenny, and D. J. Burn, "Frequency of orthostatic hypotension in a community based cohort of patients with Parkinson's disease," Journal of Neurology, Neurosurgery \& Psychiatry, vol. 75, no. 10, pp. 1470-1471, 2004.

[6] A. D. Ha, C. H. Brown, M. K. York, and J. Jankovic, “The prevalence of symptomatic orthostatic hypotension in patients with Parkinson's disease and atypical parkinsonism," Parkinsonism and Related Disorders, vol. 17, no. 8, pp. 625-628, 2011.

[7] S. Kato, M. Oda, H. Hayashi et al., "Decrease of medullary catecholaminergic neurons in multiple system atrophy and Parkinson's disease and their preservation in amyotrophic lateral sclerosis," Journal of the Neurological Sciences, vol. 132, no. 2, pp. 216-221, 1995.

[8] D. S. Goldstein, "Cardiac denervation in patients with Parkinson disease," Cleveland Clinic Journal of Medicine, vol. 74, supplement 1, pp. S91-S94, 2007.

[9] D. N. Tipre and D. S. Goldstein, "Cardiac and extra-cardiac sympathetic denervation in Parkinson's disease with orthostatic hypotension and in pure autonomic failure," Journal of Nuclear Medicine, vol. 46, no. 11, pp. 1775-1781, 2005.

[10] J. Idiaquez and G. C. Roman, "Autonomic dysfunction in neurodegenerative dementias," Journal of the Neurological Sciences, vol. 305, no. 1-2, pp. 22-27, 2011.

[11] N. Vokatch, H. Grötzsch, B. Mermillod, P. R. Burkhard, and R. Sztajzel, "Is cerebral autoregulation impaired in Parkinson's disease? A transcranial Doppler study," Journal of the Neurological Sciences, vol. 254, no. 1-2, pp. 49-53, 2007.

[12] T. Gurevich, A. Y. Gur, N. M. Bornstein, N. Giladi, and A. D. Korczyn, "Cerebral vasomotor reactivity in Parkinson's disease, multiple system atrophy and pure autonomic failure," Journal of the Neurological Sciences, vol. 243, no. 1-2, pp. 57-60, 2006.
[13] J. Naqvi, K. H. Yap, G. Ahmad, and J. Ghosh, "Transcranial Doppler ultrasound: a review of the physical principles and major applications in critical care," International Journal of Vascular Medicine, vol. 2013, Article ID 629378, 13 pages, 2013.

[14] K. Sato, T. Sadamoto, A. Hirasawa et al., "Differential blood flow responses to $\mathrm{CO}_{2}$ in human internal and external carotid and vertebral arteries," The Journal of Physiology, vol. 590, no. 14, pp. 3277-3290, 2012.

[15] A. Y. Gur, E. Auriel, A. D. Korczyn et al., "Vasomotor reactivity as a predictor for syncope in patients with orthostatism," Acta Neurologica Scandinavica, vol. 126, no. 1, pp. 32-36, 2012.

[16] H. S. Markus and M. J. G. Harrison, "Estimation of cerebrovascular reactivity using transcranial Doppler, including the use of breath-holding as the vasodilatory stimulus," Stroke, vol. 23, no. 5, pp. 668-673, 1992.

[17] C. Ratnatunga and M. Adiseshiah, "Increase in middle cerebral artery velocity on breath-holding: a simplified test of cerebral perfusion reserve," European Journal of Vascular Surgery, vol. 4, no. 5, pp. 519-523, 1990.

[18] D. S. Goldstein, "Orthostatic hypotension as an early finding in Parkinson's disease," Clinical Autonomic Research, vol. 16, no. 1, pp. 46-54, 2006.

[19] C. H. F. Camargo, H. A. Hoffmann, J. J. Luciano et al., "Orthostatic hypotension and its relationship to the clinical course of patients with Parkinson's disease," Journal of Alzheimers Disease \& Parkinsonism, vol. 4, article 155, 2014.

[20] S. H. Isaacson and J. Skettini, "Neurogenic orthostatic hypotension in Parkinson's disease: evaluation, management, and emerging role of droxidopa," Vascular Health and Risk Management, vol. 10, pp. 169-176, 2014.

[21] L. Niehaus, G. C. Böckeler, A. Kupsch, and B.-U. Meyer, "Normal cerebral hemodynamic response to orthostasis in Parkinson's disease," Parkinsonism and Related Disorders, vol. 8, no. 4, pp. 255-259, 2002.

[22] S. Angeli, R. Marchese, G. Abbruzzese et al., "Tilt-table test during transcranial Doppler monitoring in Parkinson's disease," Parkinsonism and Related Disorders, vol. 10, no. 1, pp. 41-46, 2003.

[23] B. Zamani, M. Mehrabani, S.-M. Fereshtehnejad, and M. Rohani, "Evaluation of cerebral vasomotor reactivity in Parkinson's disease: is there any association with orthostatic hypotension?" Clinical Neurology and Neurosurgery, vol. 113, no. 5, pp. 368-372, 2011.

[24] S.-J. Tsai, S.-C. Chen, T.-M. Leu et al., "Impairment of cerebral hemodynamic response to the cold pressor test in patients with Parkinson's disease," Parkinsonism and Related Disorders, vol. 15, no. 2, pp. 94-100, 2009.

[25] M. Bouhaddi, F. Vuillier, J. O. Fortrat et al., "Impaired cardiovascular autonomic control in newly and long-term-treated patients with Parkinson's disease: involvement of L-dopa therapy," Autonomic Neuroscience: Basic and Clinical, vol. 116, no. 1-2, pp. 30-38, 2004.

[26] C. Haubrich, K. Pies, M. Dafotakis, F. Block, C. Kloetzsch, and R. R. Diehl, “Transcranial Doppler monitoring in Parkinson's disease: cerebrovascular compensation of orthostatic hypotension," Ultrasound in Medicine and Biology, vol. 36, no. 10, pp. 1581-1587, 2010. 


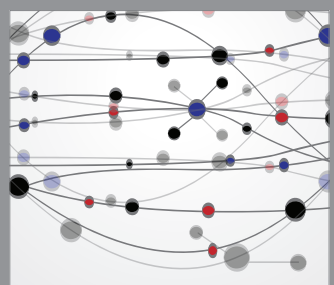

The Scientific World Journal
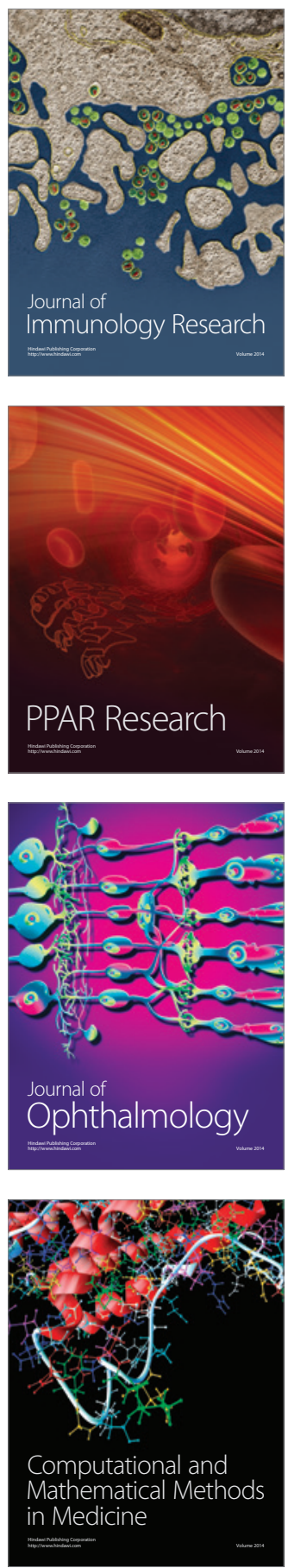

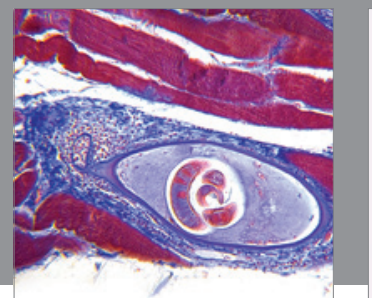

Gastroenterology

Research and Practice
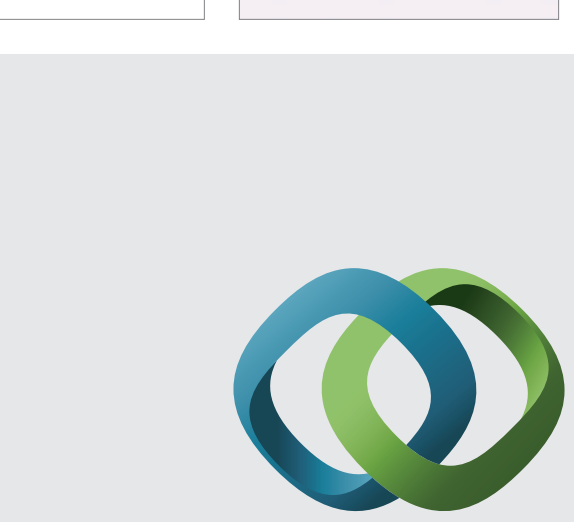

\section{Hindawi}

Submit your manuscripts at

http://www.hindawi.com
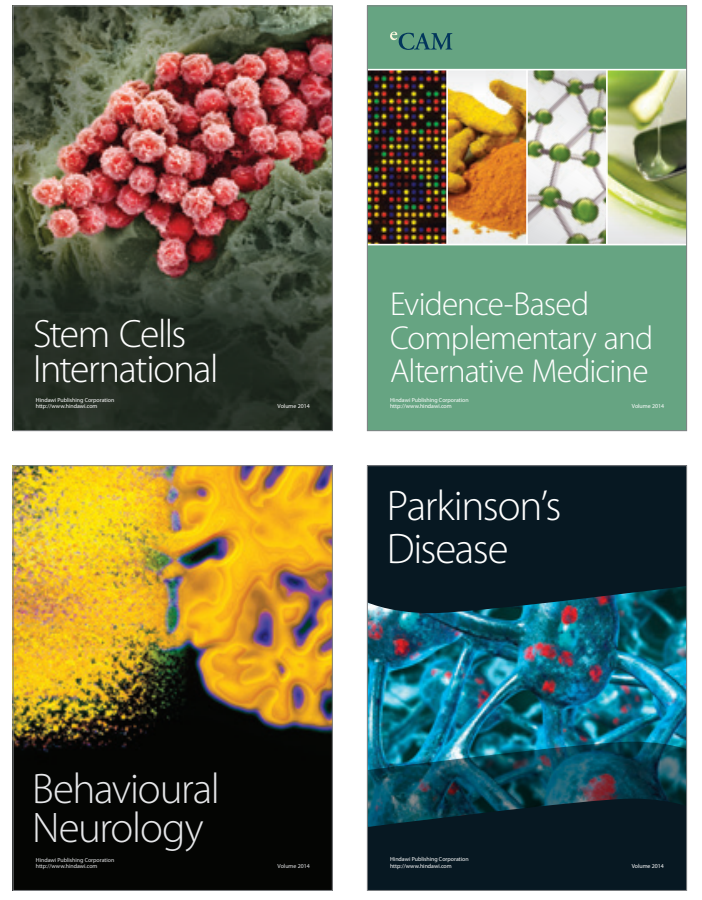
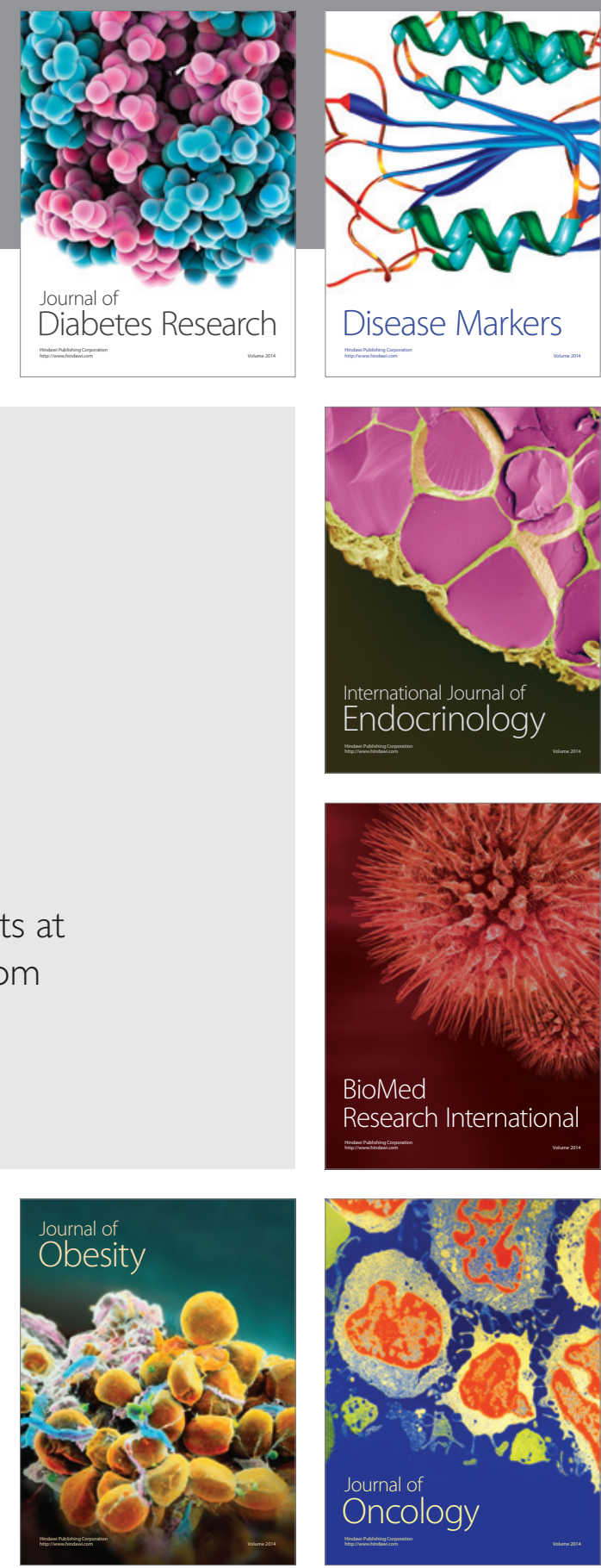

Disease Markers
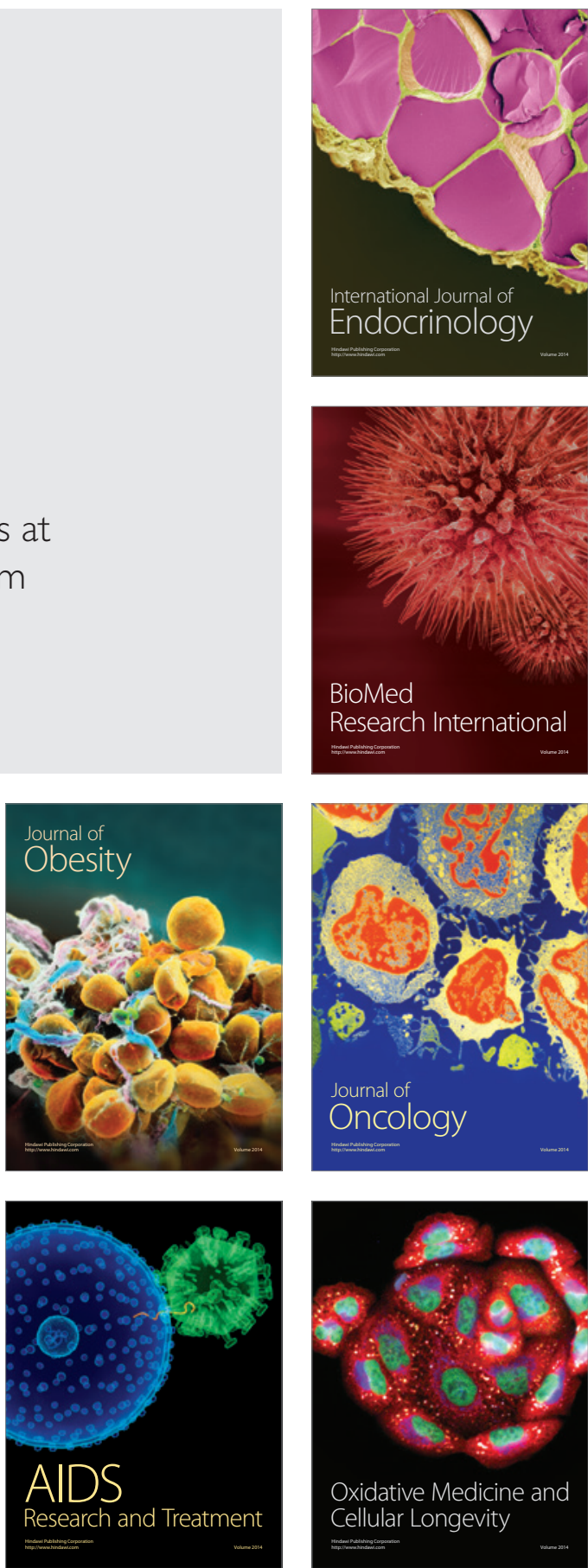